\title{
Scope Economy And Issues In Technology Management
}

\author{
Simona Sung (E-mail: sungs@mail.strose.edu), The College of Saint Rose
} John R. Norsworthy (E-mail: norswj@rpi.edu), Rensselaer Polytechnic Institute

\begin{abstract}
In the 1980s, studies of technology transfer in dual-use industries have suggested a slow down in military technology spillovers to the civilian sector. This paper takes an econometric approach to measuring the bilateral spillover effect using the airframe manufacturing industry as a case study. The diffusion of technology benefits the industrial art regardless of where technological innovation is originated. When horizontal spillover is measured as a bilateral flow of technology transfer regardless of the direction of the flow, i.e., either from military to civilian or from civilian to military, we find no evidence of a slow down, in airframe manufacturing at least, between 1961 and 1985, a period of rapid technological change in both military and commercial aircraft production. We also trace the flow of technological development in aircraft engine and measure its effect downstream on aircraft manufacturing productivity to obtain an estimate for any vertical spillover. We find a negative relationship between upstream innovation and downstream manufacturing cost, but the linkage effect is statistically insignificant. We suggest that further study should be pursued in a framework incorporating some concepts from organizational theory to better understand the differences in institutional structure that affect the adaptation and development of dual-use technologies, and the social setting that become necessary to achieve dual-use.
\end{abstract}

\section{Introduction}

During the military build-up years of the 1980s, considerable domestic and international science and technology policy discussions were generated to address the technological relationships between civilian and defense sectors of the industrial economy. Certainly, military R\&D investment was a high priority at that time and opportunity existed for a wide-range of technology transfer possibilities. Many observers expected spillover benefits from military technology investment to civilian application to be strong. Surprisingly, however, an important finding common in the various dual-use studies during that period was what seemed to be a substantial slowdown in the effects of such transfers. Alexander and Mitchell (1984) concluded that market strategies of companies in dual-use industries tended toward specialization rather than collaboration. ${ }^{1}$ Carter (1988) observed that for some dual-use companies, engineering, marketing and bookkeeping climates were too different to attempt to marry them together and that eventually such segregation might have made the two sectors diverge technically, as each created its own path of technological advance. ${ }^{2}$ Gustafson (1988) noted a reversal of the direction of technology transfer. ${ }^{3} \mathrm{He}$ found, in some cases, cutting edge technologies developed for commercial application had been taken off the shelf to apply to military uses, such as computer-aided design and manufacturing. In sum, the studies near the close of the 1980s found manufacturing technologies in dual-use industries to have become more divergent. These studies suggest that spillover benefits in the 1970s and the 1980s have not matched those earlier achievements in terms of product development, process designs and international competitiveness. In the decade of the 1980s, federal funding for defense R\&D increased sharply while civilian competitiveness in some high technology markets steadily declined.

Readers with comments or questions are encouraged to contact the authors via email. 
This paper undertakes an econometric study to verify and address some of the issues of dual-use technology transfer using airframe manufacturing (SIC 3721), the core of the larger aerospace industries, as the industry of focus. The results of our findings have important relevance in light of the renewed emphasis of military investment in the present day context. We have three objectives:

1. understand the nature and sources of technological change in U.S. airframe manufacturing - a dual-use industry - in a production context.

2. quantify the effects of economies of scope (the 'horizontal spillover'), i.e., technology transfer within a given industry, either from military to civilian or from civilian to military, and test the hypothesis of a slowdown in bilateral spillover.

3. measure the linkage effect. The goal is to trace the flow of technology developed for aircraft engines and measure its effects downstream on aircraft manufacturing productivity.

Our estimating model maps the production behavior of the aircraft industry using a translog cost function for the period between 1961 and 1985. The 1950s and 1960s bore witness to many good ideas and success stories in technological spillovers in the aircraft industry. However, consistent reporting on airframe manufacturing did not become available until 1958. For the engine sector (SIC 3724), it was not until 1960 when data closure was complete and systematic. The build-up started in the 1970s and reached its peak from 1980 to 1987 during the Reagan Administration. The Standard Industry Classification was revised in 1987, somewhat disrupting the consistency of the data. Thus we have elected to end the series at 1985 in order to preserve the integrity of the data to the maximum extent possible. The period from 1960 to 1985 was considered to be the most relevant and encompassing to our study of dualuse.

Airframe manufacturing has demonstrated remarkable success in both technology transfer and product innovation. It was also the only high-technology/high-value manufacturing group that has consistently contributed over $\$ 10$ billion each year since 1980 in reducing trade deficits of the United States. ${ }^{4}$ Like many other dual-use industries, the aircraft industry also faced a growing tendency toward specialization. The aircraft engine industry is a major upstream supplier to airframe manufacturing and is often an important driving force for the advent of new generations of high performance aircraft. The aircraft engine industry is added in our study for its linkage characteristics.

We found input demand conditions to be well behaved and technological change was production-workerssaving and non-production-workers-using. Contrary to earlier studies, we found no evidence of decline in horizontal spillover in airframe manufacturing. Horizontal spillovers, or economies of scope, were large in airframe manufacturing for the entire period from 1961 to 1985 and remained high in the second half of the period under consideration. While large, the spillover did become less significant between 1972 and 1985 . Thus our finding pertaining to airframe manufacturing only partially supports the observations noted by other dual-use specialists, namely that, gains historically obtained from dual-use opportunities were more variable in the more recent period. The slight loss of statistical significance, however, was not sufficient to support the hypothesis of a bilateral slowdown. We found vertical spillover between engine innovations and airframe manufacturing productivity and cost were positive and insignificant - but not trivial.

This paper is organized as follows: Section II provides a theoretical and conceptual framework for modeling airframe production in the short run. Section III specifies the functional form of the production model and derives the input demand equations for joint estimation with the variable cost function. We also discuss how horizontal and vertical spillover effects are measured in this section. Data requirement and construction are described in Section IV. Section V reports our estimation results. Empirical significance and policy implications of our findings are discussed in Section VI. Concluding remarks are provided in Section VII. 


\section{Theoretical Framework and Specification}

The production function specifies an output quantity $\mathrm{Y}$ as a function of quantities of inputs and an exogenous production technology $\mathrm{T}$ used in the process. A total cost function can be used to describe production behavior insofar as all cost functions are derived from the production function. However, rates of technological advance in airframe manufacturing were rapid between 1961 and 1985 and the industry experienced major cyclical demand changes for their products. Consequently, a long run cost function with instantaneous adjustment of inputs (including capital) to current input prices and output level is inappropriate for our production function. To circumvent this problem, we use a restricted variable cost function (RVCF) to postulate short run production behavior. ${ }^{5}$ The RVCF is a disequilibrium model in quantities of quasi-fixed capital and is written as:

$$
\mathrm{VC}=\mathrm{f}\left(\mathrm{P}_{\mathrm{i} \ldots \ldots \mathrm{n}}, \mathrm{Y}_{\mathrm{w}}, \mathrm{Y}_{\mathrm{c}}, \mathrm{K}, \mathrm{T}\right)
$$

where $\mathrm{VC}$ is variable cost. There are $\mathrm{n}$ variable inputs, $\mathrm{i}=1, \ldots, \mathrm{n}$, which include production workers ( $\mathrm{L}$ for labor), non-production workers ( $\mathrm{N}$ for scientists, engineers and other technical staff), materials $(\mathrm{M})$, and purchased services (S). $P_{i}$ is the price of the $i^{\text {th }}$ input. $Y_{w}$ is the level of military output and $Y_{c}$ is the level of civilian output, both in constant dollars; $\mathrm{K}$ is the level of fixed capital; $\mathrm{T}$ represents a production technology.

The restricted variable cost function assumes that firms seek short run cost minimization in production in a sequence of decision that defines their growth paths. Dual-use industries typically may not exhibit cost-minimizing behavior, at least not in the military segment of their operation, where partially completed products with long production periods may or may not be posted as output in the current accounting period. We believe that the cost minimizing condition is not as strong as commonly thought (Norsworthy and Jang, 1992). ${ }^{6}$ Specifically, since capital is treated as exogenously determined, the model is consistent with cost sharing for plant and equipment by the Department of Defense and defense contractors. Decision-makers employing the inputs face a fixed price for each input and that the input price is independent of the quantity of input purchased. In dual-use industries, once a contract is established, input prices are generally fixed or outside the control of the contractors making short run decisions. Even if a defense contractor is more likely to be tolerant of price increases than the civilian counterpart, the input prices faced by the decision-maker at any point in time are likely to be fixed.

There is no doubt that military aircraft suppliers face less stringent cost minimization incentives than the civilian manufacturers. Nevertheless, decision-makers operating on weapons contracts are conscious of cost containment issues; there have been numerous occasions in the past when the Defense Department admonished contractors of cost overruns and put considerable pressure on the companies to cut costs. ${ }^{7}$ Any gross departure from cost minimization would be revealed as a variable cost function that is non-concave in variable inputs. In the estimation results, we have encountered no instances of perversely sloping input demand functions. While the lack of such evidence does not guarantee cost minimization, it is consistent with cost-minimizing behavior.

In general, the assumption of variable cost minimization that accompanies the translog restricted variable cost function is a strong one when applied to defense contractors. It is weaker than any alternative that permits estimation of a model of production in which economies of scale and scope and learning effects can be identified at the plant level.

\section{Functional Form of the Production Model}

A standard logarithmic variable cost function for airframe manufacturing takes the following form:

$$
\begin{aligned}
& \ln V C=b_{0}+b_{w} \ln Y_{w}+b_{c} \ln Y_{c}+b_{k} \ln K+\Sigma_{i} b_{i} \ln p_{i}+1 / 2 \Sigma_{i} \Sigma_{j} b_{i j} \operatorname{lnp}_{\mathrm{i}} \operatorname{lnp}_{j} \\
& +\Sigma_{\mathrm{i}} \mathrm{b}_{\mathrm{iw}} \ln \mathrm{p}_{\mathrm{i}} \ln \mathrm{Y}_{\mathrm{w}}+\Sigma_{\mathrm{i}} \mathrm{b}_{\mathrm{ic}} \ln \mathrm{p}_{\mathrm{i}} \ln \mathrm{Y}_{\mathrm{c}}+\Sigma_{\mathrm{i}} \mathrm{b}_{\mathrm{ik}} \ln \mathrm{p}_{\mathrm{i}} \operatorname{lnk}+\mathrm{b}_{\mathrm{wk}} \ln \mathrm{Y}_{\mathrm{w}} \operatorname{lnk} \\
& +b_{c k} \ln Y_{c} \operatorname{lnk}+b_{c w} \ln y_{c} \ln Y_{w}+b_{c w 1} \ln Y_{c} \ln Y_{w}+b_{t} T+\Sigma_{i} b_{i t} \operatorname{lnp}_{i} T \\
& +b_{t f} T_{f}+b_{t s} T_{s}+\Sigma_{i} b_{i t, s} \operatorname{lnp}_{i} T_{s}+\Sigma_{i} b_{i t, f} \operatorname{lnp}_{i} T_{f}+e_{i} \\
& \mathrm{i}=\mathrm{L}, \mathrm{N}, \mathrm{M}, \mathrm{S}
\end{aligned}
$$


where again, $\mathrm{VC}$ is variable cost, or total cost net of property income. $\mathrm{Y}_{\mathrm{w}}$ and $\mathrm{Y}_{\mathrm{c}}$ are deflated output levels of military and civilian aircraft. $\mathrm{K}$ is the Divisia aggregate of the quantities of capital structures and equipment. $\mathrm{P}_{\mathrm{i}}$ is the price of the respective variable input. $T_{\mathrm{f}}$ and $\mathrm{T}_{\mathrm{s}}$ stand for specific fuel consumption, and the thrust-to-weight ratio of the engine. The average engine technology frontier, $T$, is the inverse of $T_{f}$ multiplied by $T_{s}$. Thus the coefficient $b_{t}$ measures the linkage effect.

Parametric estimation requires data for total expenditures for production and non-production workers, materials, and purchased services, as well as variable input prices $\left(\mathrm{p}_{\mathrm{i}}\right)$. The derivative of the variable cost function with respect to the price of individual inputs yields a set of input share equations. The corresponding share equation for the airframe linkage model is:

$$
\begin{aligned}
S_{i}= & \left(p_{i} x_{i}\right) /\left(\Sigma_{i} p_{i} x_{i}\right) \\
& =b_{i}+b_{i w} \ln Y_{w}+b_{i c} \ln Y_{c}+b_{i k} \operatorname{lnK}+\Sigma_{i} b_{i j} \operatorname{lnp}_{j} \\
& +\sum i b_{i t, s} T_{s}+\sum_{i} b_{i t, f} T_{f}+\sum_{i} b_{i t} T \\
& \quad i, j=L, N, \text { M, S }
\end{aligned}
$$

Homogeneity in input prices requires the following restrictions:

$$
\begin{aligned}
& \sum_{\mathrm{i}} \mathrm{b}_{\mathrm{i}}=1 \\
& \sum_{\mathrm{i}} \Sigma_{\mathrm{j}} \mathrm{b}_{\mathrm{ij}}=0 \\
& \quad \mathrm{i}, \mathrm{j}=\mathrm{L}, \mathrm{N}, \mathrm{M}, \mathrm{S}
\end{aligned}
$$

The implied input demand functions are quantities of inputs $X_{\mathrm{i}}$ rather than input shares in variable cost.

$$
\begin{gathered}
\mathrm{X}_{\mathrm{i}}=\operatorname{VC} / \mathrm{P}_{\mathrm{i}} *\left(\mathrm{~b}_{\mathrm{i}}+\mathrm{b}_{\mathrm{iw}} \ln \mathrm{Y}_{\mathrm{w}}+\mathrm{b}_{\mathrm{ic}} \ln \mathrm{Y}_{\mathrm{c}}+\mathrm{b}_{\mathrm{ik}} \operatorname{lnk}+\Sigma_{\mathrm{i}} \mathrm{b}_{\mathrm{ij}} \ln \mathrm{p}_{\mathrm{j}}\right. \\
\left.+\Sigma_{\mathrm{i}} \mathrm{b}_{\mathrm{it}, \mathrm{f}} \mathrm{Tf}+\Sigma_{\mathrm{i}} \mathrm{b}_{\mathrm{it}, \mathrm{s}} \mathrm{T}_{\mathrm{s}}+\Sigma_{\mathrm{i}} \mathrm{b}_{\mathrm{it}} \mathrm{T}\right)+\mathrm{e}_{\mathrm{i}} \\
\mathrm{i}, \mathrm{j}=\mathrm{L}, \mathrm{N}, \mathrm{M}, \mathrm{S}
\end{gathered}
$$

where $e_{i}$ is a stochastic error term. The purchased services demand equation is arbitrarily deleted from estimation. Based on Norsworthy and Jang's (1992) discussion ${ }^{8}$, estimating input demand functions is preferable: (a) there are more independent equations therefore more degrees of freedom and (b) it isolates decision variable Xi from exogenous variables, unlike share specification. The input demand functions are jointly estimated in conjunction with the variable cost function using full information maximum likelihood method.

\section{III.a. The Measurement of Economies of Scope (Horizontal Spillover)}

The dual-use technology transfer effects within an industry are measured in terms of the cross - cost elasticity of the civilian and military outputs. Since the value of output embodies the conventional sources of increasing returns -such as gains from specialization and aggregate $R \& D$ efforts -- the cost elasticity of the civilian/military output mix measures the effect, specifically, of producing more than one line of output on reducing (or raising) cost. We use the term 'economies of scope' interchangeably with 'horizontal spillover'; in this context they both measure the savings on cost from producing a military/civilian output mix. The measurement of economies of scope does not take account of the inter-temporal structure of spillovers. There are insufficient degrees of freedom in the available data to estimate a lag structure, based, for example, on military R\&D or cumulative production of each input type. Such a specification would probably be fragile anyway. ${ }^{9}$ Since some technological advances have moved from military to civilian uses with relatively long lags (the change from propeller to jet engine) and others with shorter lags (metal forming machine tools), the coefficients of a lag structure are likely to have relatively large standard errors. Consequently we have looked at contemporaneous levels of production and relied on industry history that documents common military R\&D ancestry of military and civilian production technologies, materials, engine technologies, avionics and aerodynamic design. Thus, the $b_{c w}$ coefficient is the cross partial of $Y_{w}$ and $Y_{c}$. 


$$
\mathrm{b}_{\mathrm{cw}}=\partial \ln \mathrm{VC} /\left(\partial \ln \mathrm{Y}_{\mathrm{w}} \partial \ln \mathrm{Y}_{\mathrm{c}}\right)
$$

A negative $b_{\mathrm{cw}}$ suggests that military and civilian technologies work synergistically leading to lower variable cost. A positive $b_{\mathrm{cw}}$ suggests that some technological incompatibility between the two sectors raises cost. Viewed from a purely mathematical (interplanetary) perspective, the direction of the flow of new technology is unclear and cannot be identified by this specification of the model. Therefore, any inferences derived from estimation results regarding economies of scope are understood to mean bilateral effects.

We broke the time series into two periods: 1961-1971 and 1972-1985 and included a shift coefficient $\left(\mathrm{b}_{\mathrm{cwl}}\right)$ to detect any change in economies of scope in the second half of the period. Our assumption based on the history of the industry is that the primary direction of flow is from military to civilian applications, with possible reverse flows also in the more recent years. ${ }^{10}$ This interpretation of $b_{\mathrm{cw}}$ will be reinforced or rejected by the time pattern of the coefficient: if its value increases after 1972, our bench year, the result will be consistent with the widely cited redirection of military $\mathrm{R} \& \mathrm{D}$. A larger $\mathrm{b}_{\mathrm{cw}}$ would confirm the speculation that technologies developed since the late 1960s were more specialized with less potential for near term civilian application, such as stealth and hypersonic technologies, VISTOL aircraft, etc., and the effect of the divergent technologies on manufacturing costs was expensive. If $b_{\mathrm{cw}}$ is negative and declines after 1972 relative to the entire period, then such synergy existed between 1961 and 1985 and remained strong since 1971.

\section{III.b. The Linkage Effect (Vertical Spillover)}

In the dual-use literature, researchers typically measured spillover activities by an industry's R\&D outlays. While R\&D expenditures are perhaps the most essential factor that stimulates endogenous technological change, the long lead-time to major applications and the measurement of their spillover magnitude remain difficult areas in econometric modeling. So far, the focus of spillover measurement has been chiefly on R\&D variables, and the common assumption is that the spillover is proportional to the sending industry's R\&D expenditures. Alternatively, Berndt and Morrison (1991) have attempted to account for the productivity growth in the computer industry by adjusting the figures for capital equipment in US manufacturing upward according to their computer content. ${ }^{11}$ For a discussion of the various approaches to measuring effects of R\&D spillovers, we refer the reader to Griliches' 1991 NBER paper on 'R\&D, Patents, and Productivity'. 12

The approach to measuring vertical spillover in this paper focuses on the cost effects of inter-industry technology flow, treating performance characteristics of the upstream engine product as a potential source of downstream productivity growth. Five performance characteristics of the engine are conventionally rated to reflect engine efficiency. They are: the thrust-to-weight ratio, thrust specific fuel consumption, and three design/performance characteristics (turbine inlet temperature, compression ratio, and thrust pounds per unit of cross section area of the engine). ${ }^{13}$ Any one or several of these performance characteristics may serve the purpose. The model that best fits empirical data is described by two engine quality improvement indexes -- the specific fuel consumption $\left(\mathrm{T}_{\mathrm{f}}\right)$, thrust-toweight ratio $\left(\mathrm{T}_{\mathrm{s}}\right)$-- and their composite index $\mathrm{T}$, measured by the product of $\mathrm{T}_{\mathrm{s}}$ and $\left(\mathrm{T}_{\mathrm{f}}\right)^{-1}$. The estimated technology coefficients measure the impact of changing engine characteristics on the cost of manufacturing aircraft. The chosen efficiency rating represents an envelope of aeronautical technology that stands for the state-of-the-art in engine production. By treating the quality-adjusted engine input as a factor in airframe production, we can then analyze the downstream industry's response to the technologically advanced engine input.

\section{Data Construction and Transformation}

\section{IV.a. Prices of Production and Non-production Workers}

The principal source of labor data series is Census Bureau's Annual Survey of Manufactures (ASM). These measures omit significant supplemental labor costs (SLC), which are employers' payments for social security, health insurance, pension contributions and other benefit programs. Supplemental labor costs are published annually in the ASM. To measure labor cost more accurately, we adjusted wages and salaries by including supplemental labor costs for 
production and non-production workers, distributed according to the workers' relative shares in total payroll. The price of production workers $\left(\mathrm{P}_{\mathrm{L}}\right)$ is total payments to production workers (wages plus $\mathrm{SLC}_{\mathrm{L}}$ ) divided by hours worked resulting in an hourly compensation index. The price of non-production workers $\left(\mathrm{P}_{\mathrm{N}}\right)$ is total payroll minus wages plus non-production workers' share of the supplemental labor costs, and divided by the number of non-production workers in the industry. These procedures yield annual indexes of compensation for each worker category.

\section{IV.b. Prices of Materials and Purchased Services}

Construction of a materials price requires deflationary adjustment. In the aircraft manufacturing industry, 54 different intermediate materials accounted for the top $99 \%$ of the industry's purchased inputs. The intermediate materials were extracted from Input-Output Tables of 1958, 1963, 1967, 1972, 1977 and 1982. Of the 54 intermediate inputs, 36 were physical materials, ranging from machine tools, rubber and iron to engines and scientific instruments. Eighteen were purchased services, such as accounting, financial and legal services; electric, water and gas, wholesale and transportation services. These intermediate inputs were weighted according to their relative shares in the total cost of intermediate inputs for each census year. The resulting weights $\left(\mathrm{w}_{\mathrm{i}}\right)$ were then interpolated annually between inputoutput years. Price deflators for all intermediate materials were taken from the Office of Business Analysis' Output Data Tape. ${ }^{14}$. The Divisia price index for physical materials and purchased services were computed as:

$$
\begin{array}{lr}
\mathrm{P}_{\mathrm{m}}=\Sigma_{\mathrm{i}} \mathrm{p}_{\mathrm{i}}^{\mathrm{m}} * \mathrm{w}_{\mathrm{i}}^{\mathrm{m}} & \mathrm{m}=1,2, \ldots \ldots, 54 \\
\mathrm{P}_{\mathrm{s}}=\Sigma_{\mathrm{i}} \mathrm{p}_{\mathrm{i}}{ }^{\mathrm{s}} * \mathrm{w}_{\mathrm{i}}^{\mathrm{s}} & \mathrm{s}=1,2, \ldots \ldots, 36
\end{array}
$$

where $\mathrm{m}$ stands for 54 physical materials and s for 36 different services in airframe manufacturing.

\section{IV.c. The Stock of Capital}

The stock of fixed capital is the aggregate of net stocks of structures and equipment in constant dollars. Industry investment series are available in the ANALYSIS Capital Stock Data Base from 1958 to 1981. Perpetual inventory method is used to accumulate structures and equipment at the geometric depreciation rates computed for the aircraft industries by Hulten and Wykoff. ${ }^{15}$. The gross return to capital, or property income, is total revenue net of labor compensation and of the costs of materials and purchased services. Since the model is explicitly short run, economic profits or losses are allowed: quasi- rents or disequilibrium returns are attributed to the quasi-fixed capital input.

We follow Fraumeni and Jorgenson (1981) in our definition of property income with one modification. ${ }^{16}$ The traditional computation of the internal rate of return -- based only on physical capital -- ignores financial assets. Structures and equipment comprise the firm's physical capital, but they are not the only capital firms employ. Financial assets are also corporate capital on which a rate of return must be earned. The inclusion of financial assets (from Compustat data) permits more consistent measurement of the internal rate of return, and one that corresponds more closely to that computed by the companies. The rate of return to aggregate capital is then property income divided by the sum of physical and financial assets, which is the short run internal rate, consistent with our RVCF specification.

$$
\text { ratert }=\mathrm{CK} /(\mathrm{phyA}+\mathrm{FA})
$$

where ratert is the internal short run rate of return, CK is property income -- or gross return to capital, phyA is Divisia aggregated physical assets, and FA represents financial assets.

The service price of capital from 1958 to 1981 is in turn derived using the Jorgenson and Fraumeni approach as adopted by Norsworthy and Jang (19 ):

$$
\begin{aligned}
\mathrm{p}_{\mathrm{i}, \mathrm{t}}=(1- & \text { crpitx } \left.* \text { pvdep }_{\mathrm{i}}-\text { invtcr }\right) /(1-\text { crpitx }) \\
& *\left[\mathrm{p}_{\mathrm{ai}, \mathrm{t}-1} * \text { ratert }-\left(\mathrm{p}_{\mathrm{ai}, \mathrm{t}}-\mathrm{p}_{\mathrm{a}, \mathrm{t}-\mathrm{1}} * \delta\right)+\mathrm{p}_{\mathrm{ai}, \text { new }} * \mathrm{crptx}\right]
\end{aligned}
$$


where i refers to structure or equipment, crpitx is corporate income tax rate, pvdep $\mathrm{p}_{\mathrm{i}}$ is present value of tax-allowed depreciation deduction on each dollar's investment on structure or equipment, invtcr is investment tax credit, $p_{\mathrm{a}, \mathrm{t}}$ is asset price of structure, or equipment at time $t$ and crptx is the corporate property $\operatorname{tax}^{17}$. The term $\mathrm{P}_{\mathrm{a}, \mathrm{t}, \mathrm{t}}-\mathrm{P}_{\mathrm{a}, \mathrm{t}, \mathrm{l}}$ is the capital gain on the asset.

For the four years after 1981, the shares of different types of structure and equipment in total capital expenditures used by the aircraft industry are computed from the Capital Flow Tables in the 1977 Input-Output Study. Survey of Current Business (SCB) publishes implicit price deflators for structures and equipment. Based on these price and quantity series, we constructed the service price of capital for the years 1982-1985 using parallel methods.

An overall index of the short run service price of capital can be obtained by Divisia aggregation of structures and equipment for each year divided into the property income. The annual constant dollar series from the Divisia procedure is the desired index of the level of capital stock. This value is the basis for capacity utilization and returns to scale in successive short run production periods. The capital input in each period is proportional to the capital stock at the beginning of that period. Capacity utilization is then defined as the ratio of the short run shadow cost of capital to its long run service price, following Berndt and Fuss (1986)

\section{IV.d. The Measurement of Output}

The fundamental accounting identity for production sets total cost equal to the total value of output. The identity is maintained because property income absorbs any profit or loss firms might have. The value of output is given by the sum of industry shipments and change in inventory measured in current dollars. There are detailed and separate values of shipments for military and civil aircraft for manufacturing census years, making this particular measurement relatively straightforward. But for other years, engine services, parts, $R \& D$ expenditures and secondary products have to be separated and distributed between military and civilian output. Aggregate change in inventory values, which include changes in finished goods, work in process and raw materials inventories are available in the Annual Survey of Manufactures; but no disaggregation of military and civilian inventories is given, so that those must be distributed. Each category -- the change in raw materials, work in process and finished goods -- is distributed according to shares of military and civilian back orders in total backlog, with inventory treated as proportional to backlog. Backorder data are taken from Aircraft Facts and Figures. ${ }^{18}$ Once we obtain the costs of military output and civilian output, the constant dollar levels can be computed by deflating the costs. The price deflator for commercial aircraft is available in the aforementioned ANALYSIS data tape. The military aircraft price deflator is published in the Survey of Current Business under the heading of Government Purchases. The resulting constant dollar military and civilian outputs are the levels of output we seek for the production model.

\section{IV.e. Technology Quality Index}

Performance characteristics of aircraft engines are used to link the effect of technological change in engines to downstream productivity gains in aircraft manufacturing. The five basic performance characteristics we examined were, as noted earlier: the engine's thrust-to-weight ratio, thrust-specific fuel consumption, turbine inlet temperature, compression ratio, and thrust pounds per unit of cross section area of the engine. Since jet engines define the state-ofthe-art for military and civilian aircraft, and jet engine technology was already established in 1961, engines with the greatest thrust capability were tracked for analysis. We also limited the analysis to the civilian sector since military engine performance ratings were often undisclosed. After careful examination of the data in Jane's All the World's Aircraft (1985) we decided to track Pratt and Whitney's high power JT4A, JT3D, and the various versions of JT9D engines for specific fuel consumption $\left(\mathrm{T}_{\mathrm{f}}\right)$ at maximum cruising speed. The highest thrust-to-weight ratio $\mathrm{T}_{\mathrm{s}}$ were taken to represent the state-of-the-art of technology. In the production model, both $\mathrm{T}_{\mathrm{f}}$ and $\mathrm{T}_{\mathrm{s}}$ were included as first order variables affecting airframe manufacturing cost. The variable $\mathrm{T}$ in the linkage model is a technological index arrived at by multiplying the inverse of $T_{f}$ by $T_{s}$. The corresponding coefficient $b_{t}$ measures the average effect of new engine technology on airframe manufacturing cost. Coefficients $b_{t}, b_{t f}$ and $b_{t s}$ measure the average rates of technological change 
whereas $b_{i, t} b_{i, t}$, and $b_{i, t s}$ measure biased technological change in variable inputs attributable to the new engine technology.

\section{Estimation Results}

\section{V.a. Production Structure and Factor Substitutability}

Table 1 shows the own and cross price elasticities of demand for production inputs in airframe manufacturing. The own price elasticity of demand for input $\mathrm{i}$ is defined as:

$$
\text { PEDII }=\left(b_{i}\right) *\left(b_{i}+s_{i}^{2}-s_{i}\right) / s_{i}^{2}
$$

where $s_{i}$ represents the share of input $i$ in variable cost. We found production workers (own price elasticity PEDLL) to exhibit highly elastic demand condition, especially in the more recent years of the study. The result suggests persistent and large employment losses in this industry between 1961 and 1985, particularly during periods of rising wages. This may have resulted from increased use of automation in the plants as well as the trend to contracting out maintenance and business services. The services input exhibits declining but large own price elasticities of demand. The coefficient $b_{k}$ that measures the effect of capital investment on variable cost of production, is -0.13 (-6.0989). Apparently, a onepercent increase in the investment of structures and equipment comprising the production plant has the effect of reducing variable cost by about .13\%. This seems to suggest economies of scale. Diminishing price elasticity suggests an increase in input share. The finding matches the reported historical industry data. Table 2 shows a nearly three-fold increase in the share of purchased services between 1961 and 1985 in airframe manufacturing. The demand functions for non-production workers and materials input are price inelastic. Quantities demanded of these inputs have not changed much as their prices moved.

\section{V.b. Horizontal Spillover Effects - Economies of Scope}

We find that over the 25-year period, the airframe manufacturing industry's specific technical capabilities have allowed efficiencies wrought by variety. The overall scope coefficient $b_{c w}$ is $-0.25(-3.3320)$ for the entire period. Manufacturing spillover effects have been positive in airframe manufacturing. They have contributed to reducing annual manufacturing costs by about $0.25 \%$ for each $1 \%$ increase in the mix of the levels of military and civilian output between 1961 and 1985.

\section{V.b.i. Testing the Hypothesis of a Slowdown in Technology Transfer}

To test the hypothesis that increasingly more specialized production behavior characterized the industry in the 1970s and 1980s, the data were divided into two periods using 1972 as benchmark, as discussed earlier. The shift coefficient $b_{\mathrm{cw} 1}$ was used to capture any change in economies of scope - the cross elasticity of costs between 1972 and 1985, a period in which the divergence of manufacturing technology is believed to have accelerated. Within this structure, the latter period adjustment to the economies of scope coefficient, $b_{\mathrm{cwl}}$, is -0.31 (Table 3 ) and insignificant. While in strict statistical terms this coefficient suggests no significant difference in spillovers since 1972, the magnitude is quite large and cannot be ignored. The second period scope economy, $b_{\mathrm{cwx}}$, which is computed as the sum of $b_{\mathrm{cw}}$ and $\mathrm{b}_{\mathrm{cw} 1}$, is also large (-0.57) and significant (2.9222). Thus, we find no evidence of diminishing bilateral spillover in airframe manufacturing. To the contrary, we find substantial increase in the spillovers in the later period.

\section{V.c. Vertical Spillover - The Linkage Effect ${ }^{19}$}

When three indexes of upstream engine performance characteristics are entered into the cost function of airframe manufacturing, the average rate of technological change in the engine, $b_{t}$, has a negative impact on aircraft production cost. Improvements in overall engine technology have a negative cost elasticity (-0.062) in downstream manufacturing. However, all of the three upstream engine innovation indexes $\left(b_{t}, b_{t f}, b_{t s}\right)$ are negatively associated with 
short run airframe manufacturing cost, though all are statistically insignificant. Thus, upstream innovation-induced productivity gain in aircraft manufacturing is not verified by our study.

\section{Empirical Significance and Policy Implications}

Dual use industries, such as semiconductors, computers, magnetic alloys, fiber optics, laser application to manufacturing and aerospace, are at the forefront of modern technology and innovation. Market shares in these industries largely depend on directed procurements and product development and innovations are technology-driven. Since military R\&D efforts in the U. S. account for about a half of the total national investment in science and technology during the period studied, the dual-use nature of these industries is an important source of advanced technologies. Without common objectives and strong commercial incentives to encourage diffusion to commercial applications, the transformation of military to civilian application would almost certainly not take place to the observed degree.

The empirical findings raise two immediate issues for technology policy. First, given that technology transfer can go both ways, a large defense expenditure may carry the high risk of diverting talent and funds from civilian applications. In the 1980s, many dual-use experts had expressed concerns for the disproportionate concentration of investment in research and development in acutely specialized military technology without proper attention for the important 'middle ground' where technology is diffused for applied civilian research ${ }^{20}$. This concern is still relevant today. A policy orientation that crowds out private research might in the longer run also weaken the defense industry itself. $^{21}$ Defense expenditures gained at the cost of civilian R\&D share in the total budget may have long-range grave consequences in global competitiveness. Furthermore, in periods of defense cutbacks, economies of scope based on the transfer of technology from the military to the private sector can be expected to diminish. There is strong evidence that there is a two-way flow of technology transfer - by the 1980s, many commercial technologies were ahead of established military practices. For example, CAD/CAM was commercial technology available for military application; alloy materials and semiconductor chips developed in the civilian sector were superior in quality and cheaper in cost. The company-funded research and development in consumer electronics later revolutionized commerce and the way of life in general. It is important that continual civilian R\&D efforts be encouraged and supported to help fill the research and innovation vacuum that may result from reduced military procurement and R\&D support.

Secondly, econometric studies are useful for estimating the direction and magnitude of the relationships being studied, but more specific relationships based on a pivotal subset of issues regarding particular dual-use engineering technologies and management mechanism at the plant and research laboratory levels need to be examined. Simulation and institutional studies can better identify the key obstacles interfering with technology transfer, as well as those types of promising opportunities that may be overlooked in quantitative studies. For example, scholars of dual-use technology have pointed out that dual-use exists in special functional contexts. So, what types of institutional setting have worked and what have not? What is required of the institutional environment that renders minimum obstruction to the realization of the fullest spillover gains? What are the technological capabilities of and the process by which downstream industries absorb new technologies as they are developed?

It is generally thought that the greatest economies of scope in dual use industries are realized by the small parts and subsystems contractors - and these second and third-tier manufacturers typically do not perform research activities on their own. What, then, can be done to retrieve the important yet forfeited dual-use information? In the aircraft jet engine industry for example, strong linkages are believed to exist between defense and commercial research laboratories since jet engines are co-developed by both defense and non-defense sectors. If co-development is the criterion for successful civilian use of military technologies, then what is the appropriate industry policy to make the structures and culture of military/civilian technology systems more compatible to improve the utilization of science and technology for both economic and military strength ${ }^{22}$ 
Table 1: Own Price and Cross Elasticities of Demand: Airframe Manufacturing

\begin{tabular}{|c|c|c|c|c|c|c|c|c|c|c|}
\hline Year & PEDLL & PEDNN & PEDMM & PEDSS & PEDLN & PEDLM & PEDLS & PEDMN & PEDMS & PEDNS \\
\hline 1961 & -1.42498 & -0.280328 & -0.614337 & -2.88614 & -0.360757 & 1.07864 & 0.718793 & 0.223897 & -0.067130 & 0.152823 \\
\hline 1962 & -1.37866 & -0.299291 & -0.656332 & -3.29386 & -0.305742 & 1.01410 & 0.674153 & 0.245798 & -0.085345 & 0.134882 \\
\hline 1963 & -1.39845 & -0.298362 & -0.644417 & -3.06496 & -0.320655 & 1.03662 & 0.693931 & 0.244763 & -0.077899 & 0.140186 \\
\hline 1964 & -1.46618 & -0.243830 & -0.619061 & -2.64362 & -0.418679 & 1.10290 & 0.758562 & 0.194997 & -0.060506 & 0.173712 \\
\hline 1965 & -1.50018 & -0.274595 & -0.615014 & -2.55614 & -0.419943 & 1.12985 & 0.788921 & 0.218383 & -0.056446 & 0.165934 \\
\hline 1966 & -1.51787 & -0.272996 & -0.618874 & -2.48837 & -0.434327 & 1.13918 & 0.805961 & 0.216833 & -0.054472 & 0.169303 \\
\hline 1967 & -1.51606 & -0.215650 & -0.588917 & -2.23685 & -0.470616 & 1.16245 & 0.816930 & 0.179989 & -0.036229 & 0.201116 \\
\hline 1968 & -1.52159 & -0.218922 & -0.570806 & -2.16541 & -0.473028 & 1.18141 & 0.825760 & 0.182007 & -0.028590 & 0.204457 \\
\hline 1969 & -1.59104 & -0.278523 & -0.594395 & -2.24631 & -0.483791 & 1.21187 & 0.878192 & 0.222628 & -0.037801 & 0.179015 \\
\hline 1970 & -1.56234 & -0.267385 & -0.576630 & -2.14674 & -0.472154 & 1.20573 & 0.860400 & 0.213007 & -0.028424 & 0.189422 \\
\hline 1971 & -1.59007 & -0.257322 & -0.576269 & -2.08200 & -0.500869 & 1.22617 & 0.887926 & 0.205262 & -0.023911 & 0.197520 \\
\hline 1972 & -1.65973 & -0.249185 & -0.651583 & -2.26523 & -0.560055 & 1.21641 & 0.935408 & 0.197571 & -0.050540 & 0.188729 \\
\hline 1973 & -1.67719 & -0.212640 & -0.654963 & -2.21809 & -0.594426 & 1.22685 & 0.953162 & 0.176718 & -0.048575 & 0.203132 \\
\hline 1974 & -1.52297 & -0.269361 & -0.544503 & -1.93605 & -0.441245 & 1.20449 & 0.844291 & 0.215476 & -0.006663 & 0.204883 \\
\hline 1975 & -1.48583 & -0.262769 & -0.557574 & -1.90819 & -0.419515 & 1.16735 & 0.816920 & 0.209814 & -0.006305 & 0.209887 \\
\hline 1976 & -1.57044 & -0.253022 & -0.570876 & -1.90789 & -0.489122 & 1.21639 & 0.885906 & 0.202320 & -0.859971 & 0.213371 \\
\hline 1977 & -1.52048 & -0.267161 & -0.568559 & -1.88981 & -0.441257 & 1.18250 & 0.846589 & 0.213084 & -0.646162 & 0.210028 \\
\hline 1978 & -1.60863 & -0.226683 & -0.563606 & -1.84949 & -0.534217 & 1.25036 & 0.923640 & 0.186330 & -0.154810 & 0.227814 \\
\hline 1979 & -1.57282 & -0.157857 & -0.516318 & -1.74750 & -0.536619 & 1.26424 & 0.905204 & 0.157820 & 0.017781 & 0.259433 \\
\hline 1980 & -1.65569 & -0.247532 & -0.365229 & -1.54248 & -0.558009 & 1.45827 & 1.00594 & 0.202406 & 0.068004 & 0.263291 \\
\hline 1981 & -1.72085 & -0.197255 & -0.564017 & -1.80211 & -0.635891 & 1.33425 & 1.02527 & 0.172023 & 0.034921 & 0.241848 \\
\hline 1982 & -1.69007 & -0.190852 & -0.561094 & -1.78731 & -0.614335 & 1.31328 & 1.00012 & 0.169355 & 0.005685 & 0.245398 \\
\hline 1983 & -1.75373 & -0.216393 & -0.572356 & -1.80500 & -0.653144 & 1.35253 & 1.05388 & 0.180762 & 0.001697 & 0.235797 \\
\hline 1984 & -1.77264 & -0.200631 & -0.554503 & -1.76627 & -0.675759 & 1.38211 & 1.07511 & 0.173731 & 0.009285 & 0.245009 \\
\hline 1985 & -1.76668 & -0.186724 & -0.548003 & -1.74883 & -0.676895 & 1.38297 & 1.07194 & 0.167948 & 0.012500 & 0.251174 \\
\hline
\end{tabular}


Table 2: Factor Shares in Variable Cost Airframe Manufacturing

\begin{tabular}{|c|c|c|c|c|}
\hline Year & Production Workers & Nonproduction Workers & Materials & Services \\
\hline 1958 & 0.262613 & 0.197860 & 0.497553 & $0.419749 \mathrm{E}-01$ \\
\hline 1959 & 0.221038 & 0.207438 & 0.516298 & $0.552268 \mathrm{E}-01$ \\
\hline 1960 & 0.220570 & 0.219958 & 0.505354 & $0.541182 \mathrm{E}-01$ \\
\hline 1961 & 0.207454 & 0.239580 & 0.498118 & $0.548483 \mathrm{E}-01$ \\
\hline 1962 & 0.223349 & 0.263996 & 0.466905 & $0.457500 \mathrm{E}-01$ \\
\hline 1963 & 0.222866 & 0.258456 & 0.468882 & $0.497960 \mathrm{E}-01$ \\
\hline 1964 & 0.232290 & 0.210917 & 0.494380 & $0.624133 \mathrm{E}-01$ \\
\hline 1965 & 0.204063 & 0.233696 & 0.496713 & $0.655290 \mathrm{E}-01$ \\
\hline 1966 & 0.208742 & 0.231421 & 0.491816 & $0.680209 \mathrm{E}-01$ \\
\hline 1967 & 0.201071 & 0.196130 & 0.521594 & $0.812042 \mathrm{E}-01$ \\
\hline 1968 & 0.189913 & 0.195386 & 0.530177 & $0.845238 \mathrm{E}-01$ \\
\hline 1969 & 0.192724 & 0.230605 & 0.498854 & $0.778183 \mathrm{E}-01$ \\
\hline 1970 & 0.186619 & 0.219763 & 0.510348 & $0.832695 \mathrm{E}-01$ \\
\hline 1971 & 0.175084 & 0.216031 & 0.519770 & $0.891157 \mathrm{E}-01$ \\
\hline 1972 & 0.196318 & 0.226157 & 0.493985 & $0.835406 \mathrm{E}-01$ \\
\hline 1973 & 0.191235 & 0.211342 & 0.508056 & $0.893674 \mathrm{E}-01$ \\
\hline 1974 & 0.189659 & 0.209429 & 0.507380 & $0.935320 \mathrm{E}-01$ \\
\hline 1975 & 0.175415 & 0.211421 & 0.514074 & $0.990897 \mathrm{E}-01$ \\
\hline 1976 & 0.176620 & 0.208718 & 0.513579 & 0.101083 \\
\hline 1977 & 0.172784 & 0.216391 & 0.509305 & 0.101519 \\
\hline 1978 & 0.174054 & 0.194791 & 0.523663 & 0.107493 \\
\hline 1979 & 0.158837 & 0.165004 & 0.558352 & 0.117807 \\
\hline 1980 & 0.149949 & 0.168044 & 0.561442 & 0.120563 \\
\hline 1981 & 0.155845 & 0.187035 & 0.540904 & 0.116216 \\
\hline 1982 & 0.153549 & 0.184447 & 0.543788 & 0.117995 \\
\hline 1983 & 0.148596 & 0.197269 & 0.537474 & 0.116661 \\
\hline 1984 & 0.142215 & 0.188525 & 0.548891 & 0.120369 \\
\hline 1985 & 0.140549 & 0.182595 & 0.554369 & 0.122486 \\
\hline
\end{tabular}

Historical evidence suggests that expensive military-bred technologies improved the market position of companies that adopted them because customers were willing to pay a premium for superior performance. How does today's world market influence company decisions? Critics of the commercial sector of the dual-use industries often blame the industry for failing to exploit the power of defense R\&D and put innovative product ideas to market. To what extent do ordinary market forces transform high-cost military technologies as they approach the civilian market, or are more deliberate interventions required for successful reshaping? In recent years, civilian innovations and applications increasingly precede military $\mathrm{R} \& \mathrm{D}$, particularly in the areas of information technology, magnetic alloys, battery materials, and laser applications to manufacturing. ${ }^{23}$ This broader array of innovation in new components and materials makes production technology and management much more complex because the requirements for precision and reliability are greater than ever before. What management skills then are necessary in this new production system that requires more elaborate technology integration, communication and planning, and yet risks a higher possibility of failure in systems development? In sum, the social and organizational obstacles are the fundamental barriers to enhanced spillover activities. Reducing and overcoming these obstacles are among the greatest challenges facing dual-use technology policies. 
Table 3: Estimated Coefficients - Airframe Manufacturing

\begin{tabular}{|c|c|c|c|}
\hline Variable & Coefficient & Standard Error & T-Statistic \\
\hline $\mathrm{b}_{0}$ & 0.067 & 0.0162481 & 4.14805 \\
\hline$b_{x}$ & -0.219 & 0.0234138 & -9.36818 \\
\hline$b_{1}$ & 0.168 & 0.0033156 & 50.57850 \\
\hline$b_{n}$ & 0.212 & 0.0030835 & 68.81440 \\
\hline $\mathrm{b}_{\mathrm{m}}$ & 0.523 & 0.0035949 & 145.61900 \\
\hline$b_{k}$ & -0.127 & 0.0208652 & -6.09894 \\
\hline$b_{w}$ & 0.556 & 0.0439177 & 12.65130 \\
\hline$b_{c}$ & 0.398 & 0.0441145 & 9.01633 \\
\hline$b_{11}$ & -0.029 & 0.0381697 & -0.77176 \\
\hline$b_{\mathrm{nn}}$ & 0.111 & 0.0381856 & 2.91464 \\
\hline $\mathrm{b}_{\mathrm{mm}}$ & -0.079 & 0.0521008 & -1.52356 \\
\hline $\mathrm{b}_{\mathrm{kw}}$ & 0.071 & 0.0290179 & 2.43568 \\
\hline $\mathrm{b}_{\mathrm{ck}}$ & -0.040 & 0.0370920 & -1.07210 \\
\hline $\mathrm{b}_{\mathrm{cw} 1}$ & -0.310 & 0.2497790 & -1.23998 \\
\hline $\mathrm{b}_{\mathrm{cw}}$ & -0.259 & 0.0776860 & -3.33204 \\
\hline$b_{c w x}{ }^{a}$ & -0.569 & 0.2375390 & -2.92220 \\
\hline $\mathrm{b}_{\ln }$ & -0.132 & 0.0293640 & -4.48227 \\
\hline $\mathrm{b}_{\mathrm{lm}}$ & 0.095 & 0.0424920 & 2.22438 \\
\hline $\mathrm{b}_{\mathrm{mn}}$ & 0.010 & 0.0384677 & 0.27063 \\
\hline $\mathrm{b}_{\mathrm{lw}}$ & -0.008 & 0.0065397 & -1.14948 \\
\hline $\mathrm{b}_{\mathrm{lc}}$ & 0.003 & 0.0075576 & 0.43141 \\
\hline $\mathrm{b}_{\mathrm{lt}}$ & -0.009 & 0.0124325 & -0.70864 \\
\hline$b_{n w}$ & 0.026 & 0.0061609 & 4.16558 \\
\hline $\mathrm{b}_{\mathrm{nc}}$ & -0.025 & 0.0067483 & -3.74341 \\
\hline$b_{\mathrm{nt}}$ & -0.025 & 0.0108020 & -2.33421 \\
\hline $\mathrm{b}_{\mathrm{mw}}$ & -0.011 & 0.0078035 & -1.46005 \\
\hline$b_{m c}$ & 0.015 & 0.0088933 & 1.68474 \\
\hline$b_{\mathrm{mt}}$ & 0.014 & 0.0139803 & 0.99805 \\
\hline$b_{t}$ & -0.062 & 0.0559045 & -1.10168 \\
\hline$b_{t f}$ & -0.019 & 0.0200424 & -0.95460 \\
\hline $\mathrm{b}_{\mathrm{ts}}$ & -0.148 & 0.1241570 & -1.19286 \\
\hline
\end{tabular}

a computed from estimated coefficients $b_{c w}$ and $b_{c w 1}$.

Log of Likelihood Function $=546.14$

Cost Function: $\mathrm{R}^{2}=0.99, \mathrm{DW}=1.35$

Demand Equation Statistics:

\begin{tabular}{|c|c|}
\hline Production Worker: & $\mathrm{R}^{2}=0.94, \mathrm{DW}=1.97$ \\
\hline Non-production Worker: & $\mathrm{R}^{2}=0.90, \mathrm{DW}=2.09$ \\
\hline Materials: & $\mathrm{R}^{2}=0.89, \mathrm{DW}=1.31$ \\
\hline Services: & $1, \mathrm{DW}=1.35$ \\
\hline
\end{tabular}

\section{Conclusions}

This paper has attempted to 1) understand the basic structure of production in airframe manufacturing; 2), obtain a measure of spillover resulting from possible bilateral technology transfer between the military and civilian sectors within the aircraft industry; 3) attain an estimate of vertical spillover initiated by innovations occurred in a major upstream supplier, the aircraft engine. We found productivity growth in airframe manufacturing stem from three major sources. One, substantial capital investment during periods of rising factor costs gave rise to significant substitution effects that reduced cost. Two, considerable economies of scope from the dual use of manufacturing technologies in 
military and civilian airframe output production with evidence for bilateral flows in the most recent period. Three, new engine technologies have a negative relationship to airframe manufacturing cost and productivity growth but the effects are not significant.

Our econometric models produced some very useful results. However, further study of dual-use technologies should be pursued in a framework incorporating some concepts from organization theory and studies of research and innovation, as well as conventional economic theory. Such a study should be directed toward understanding differences in organizational structure that affect the adaptation and development of dual-use technologies, and the social setting that become necessary to achieve dual-use. It should also seek to develop an agenda and supporting data for further quantitative research.

From a strategic standpoint, the understanding of how high technology industries relate to one another, the effect of technology transfer and the process by which new technologies are modified and diffused are among the most important elements in designing well-informed science and technology policies. These are important areas that need to be understood, for practical application as well as for cost-effective industrial practice.

\section{Endnotes}

1 Alexander, Arthur J., and Mitchell, Bridger M., 1984, "Measuring Technological Change of Heterogeneous Products," Rand Corporation, Santa Monica.

${ }^{3}$ Carter, Ashley B., "Anatomy of the Dual-use Relationship" (1988), paper presented at the Science, Technology and Public Policy Program Workshop on dual-use technology, Center for Science and International Affairs, Harvard University.

${ }^{4}$ Gustafson, Thane (1988), "Responses of the Soviet Military and the Military-Industrial Sector to Technological Challenge in Weapons Design, Development, and Procurement, 1965-1985", Draft for presentation at Science, Technology and Public Policy Workshop on dual-use technology, Center for Science and International Affairs, Harvard University.

5 Airframe manufacturing, aircraft engine and parts industries as a group recorded a net export of $\$ 11.8$ billion in 1986. According to Aircraft Facts and Figures, this industry group has consistently been faring well above all other high technology industries in international trade in the 1980s.

5 Contemporary discussion of the comparative merits of the total and variable cost functions are presented in Norsworthy and Jang (1992), Empirical Estimation and Analysis of Productivity and Technological Change: Application in High Technology and Service Industries, chapters 3 and 7, North Holland.

Also see Norsworthy, Jang and Shi (1991).

6 Norsworthy, John R. and Jang, Show-ling (1992), chapter 2

7 In the 1980s, the Pentagon continued its pressure on contractors to cut costs. In 1982, the Defense Secretary Caspar Weinberger was quoted as stating that the DOD was not going to be blackmailed into military weapons contracts with excessive labor costs. Quoted in Clark Mollenhoff, "Labor Pact Blackmail Is Out: Weinberger," Washington Times, August 20, 1982. P.1.

8 Norsworthy, J. R. and Jang, Show-Ling (1992), Chapter 3.

9 Fragility is used in the sense described by Leamer (May, 1993), 'Factor-Supply Differences as a Source of Comparative Advantage', American Economic Review. 
10 Note that technology transfer from civilian to military production would increase the magnitude of $b_{c w}$ and, if stronger (as seems likely) in the more recent period, $b_{\mathrm{cwl}}$ as well.

11 Berndt and Morrison (1991)

12 Griliches, Zvi. (1991) “The Search for R\&D Spillovers”, NBER Working Papers no. 3768, Cambridge, Ma.

13 Engine design performance characteristics were suggested to us in a series of conversations with Professor Robert Loewy of Rensselaer Polytechnic Institute in 1987 about engines and engine ratings.

14 The data tape was prepared by the Office of Business Analysis, US Dept of Commerce, 1987.

15 Hulten, Charles R., and Wykoff, Frank C. (1981), "The Measurement of Economic Depreciation," in Hulten, C. R. (ed.), Depreciation, Inflation, and the Taxation of Income Capital, The Urban Institute, pp. 81-132.

${ }^{16}$ Fraumeni, Barbara, and Jorgenson, Dale W. (1986), "The Role of Capital in U.S. Economic Growth, 1948-1979," Measurement Issues and Behavior of Productivity Variables, A. Dogramaci, ed. MIT Press, Cambridge, MA.

17 Ibid.

18 Aircraft Facts and Figures, 1987 - 1988.

19 These technological bias coefficients are often misinterpreted. See Norsworthy and Jang (1992, ch. 3).

20 For a discussion of national technology policy imbalance, see Branscomb, "Case of a Dual-Use National Technology Policy"; Kenneth Flamm and Thomas L. McNaugher, "Rationalizing Technology Investments,"in John D. Steinbrunner, ed., Restructuring American Foreigh Policy (Washington, D.C.: Brookings Institution, 1989), and Markusen and Yudken, Dismantling the Cold War Economy, Chapter 5.

${ }^{21}$ Walker, William (1988), 'Structural Change in the UK Defense Sector: The End of Insularity'. Paper presented at the Science, Technology and Public Policy Workshop on dual-use Technology, Center for Science and International Affairs, Harvard University.

22 Branscomb, L. (1988), 'Modes of Inter-Sectoral Technology Failures', Center for Science and International Affairs, Harvard University.

23 Gustafson, Thane. (1988), Center for Science and International Affairs, Harvard University. 